\title{
2 Cationic cellulosic derivatives as flocculants in papermaking
}

\author{
3 Roberto Aguado (ㄷ) Ana F. Lourenço • Paulo J. Ferreira • Ana Moral • \\ Antonio Tijero
}

5 Received: 22 December 2016/ Accepted: 24 April 2017

6 (c) Springer Science+Business Media Dordrecht 2017

7 Abstract Water-soluble cationic cellulose deriva8 tives were synthesized by three different procedures, 9 cationizing bleached hardwood kraft pulp with (310 chloro-2-hydroxypropyl) trimethylammonium chlo11 ride. The first procedure involved a previous depoly12 merization step with orthophosphoric acid. The 13 second one consisted on dissolving cellulose in $14 \mathrm{NaOH} /$ urea before cationization. For the third proce15 dure, the reaction medium was heterogeneous since it 16 was carried out with a part of cellulose with high 17 degree of polymerization. Oppositely to the common 18 methods, cationization occurred under mild condi19 tions. Differences among the three derivatives are 20 illustrated by X-ray diffraction patterns of pretreated 21 samples, infrared spectra, and determinations of the

A1 Electronic supplementary material The online version of A2 this article (doi:10.1007/s10570-017-1313-y) contains suppleA3 mentary material, which is available to authorized users.

A4 R. Aguado $(\square) \cdot$ A. Moral

A5 ECOWAL, Molecular Biology and Biochemical

A6 Engineering Department, Pablo de Olavide University,

A7 41013 Seville, Spain

A8 e-mail: rjagugar@alumno.upo.es

A9 A. F. Lourenço · P. J. Ferreira

A10 CIEPQPF, Chemical Engineering Department, University

A11 of Coimbra, 3030-790 Coimbra, Portugal

A12 A. Tijero

A13 Grupo de Celulosa y Papel, Chemical Engineering

A14 Department, Complutense University of Madrid,

A15 28040 Madrid, Spain degree of substitution, the zeta potential, the charge density and the molecular weight. The performance of these polyelectrolytes for the flocculation of mineral fillers used in papermaking was tested by laser diffraction spectrometry. The flocculant with the highest degree of polymerization and charge originated the best results, particularly when the filler used was kaolin, proving that water-soluble cationic cellulose derivatives can aid in the flocculation of fillers used in papermaking. On the contrary, the shortestchained derivative was not effective. The results were interpreted in terms of the characteristics of the cellulose derivatives flocculants and of the fillers, and neutralization and patching were proposed as the dominant mechanisms.

Keywords Cationization - Cellulose $\cdot$ Fillers for papermaking $\cdot$ Flocculation $\cdot$ Laser diffraction spectrometry

\section{Introduction}

Non-renewable and scarcely biodegradable polymeric aids, such as cationic polyacrylamides (CPAM) or polyethyleneimine (PEI), are often applied in paper mills to achieve good retention of mineral fillers. The particle size of these fillers is generally much smaller than the wire mesh at the forming and drainage section of the paper machine, and thus mechanical retention

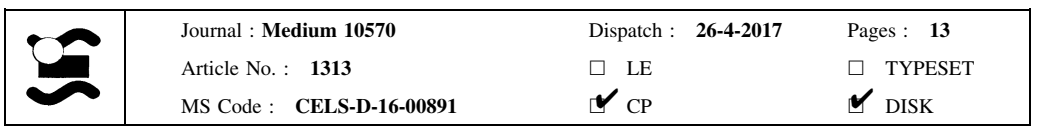


alone, if no flocculation agents are used, results in high losses (Allen 1985). Cationic polyelectrolytes, besides enhancing retention, improve the drainage behavior and sheet formation, compensating somehow the disruption of fiber bonding caused by fillers (Antunes et al. 2008a).

Environmental concerns have led to research into alternative flocculation agents to be used in different fields, dedicating efforts to obtain cleaner and/or cheaper polyelectrolytes from natural and renewable sources. Introducing cationic ammonium groups into polysaccharides has been the answer for many researchers, given their availability and biodegradability. Starch, guar gum, cellulose, dextran and chitosan, among others, have been proved useful (Wood and Mora 1963; Prado and Matulewicz 2014). Nonetheless, while cationic starch and cationic guar gum have found good markets in the manufacturing industries (QY Research 2017), the production of cationic derivatives from the most abundant and available of all polysaccharides, cellulose, remains scarce. Although they are sold as cosmetic ingredients (Kozubal et al. 2014), their potential in the paper industry is being missed.

Yan et al. (2009) produced water-soluble cationic cellulose (WSCC) from microcrystalline cellulose to enhance flocculation in wastewater treatments. A similar procedure, i.e., dissolving short-chained cellulose in $\mathrm{NaOH} /$ urea and then performing cationization in a homogeneous medium, was followed by $\mathrm{Li}$ et al. (2015) aiming at using it as filler modifier. Other authors started from chemically modified cellulose, e.g., cellulose acetate and hydroxyethyl cellulose, as raw materials to obtain WSCC (Liesiene 2010; Liesiene and Kazlauske 2012). Those substrates consisted of alkali-soluble cellulose or modified cellulose with low degrees of polymerization (DP). The resulting cationic derivatives, obtained by means of epoxypropyltrimethylammonium chloride (EPTAC) or (3-chloro-2-hydroxypropyl) trimethylammonium chloride (CHPTAC), were not only soluble in aqueous alkaline solutions but also in water. However, solubilizing wood pulp in aqueous media is much tougher. Actually, total dissolution of high-DP Q1 $\alpha$-cellulose may be simply impossible (Qi et al. 2011). Short-chained WSCC may be adequate for flocculation by charge neutralization, as long as particles with negative zeta potential at the working $\mathrm{pH}$ are involved, but due to its small DP, it is not a good option for flocculation by bridging, which is the primary mechanism of particle aggregation in the first stage of the process. In fact, it was proved that the bridging mechanism dominates when polymers of high molecular weight and medium charge density are used (Rasteiro et al. 2008a).

In order to obtain high molecular weight WSCC, solubility in water must be achieved by the introduction of enough ionic groups into high-DP cellulose, such as that from wood. Previous studies report the production of cationic fibers with a degree of substitution around 0.2 , which can be useful for some applications, but is still too low to promote solubility (Moral et al. 2016).

Cellulose-based polyelectrolytes from birch wood pulp were produced by Liimatainen et al. (2011) and Sirviö et al. (2011). Instead of using $\mathrm{NaOH}$ and CHPTAC or EPTAC, they performed a previous oxidation step with sodium periodate, and then cationized the substrate with Girard's reagent. They were able to incorporate more than one cationic group per monomer, thus obtaining a very high degree of substitution (and consequently high charge density). In spite of its high DP, this polymer was water-soluble due to its high ionic character. However, to simultaneously improve retention and drainage in papermaking, an agent of medium charge density is more appealing than a highly charged one, as the latter adopts a conformation that favors patching but hinders bridging (Antunes et al. 2008b).

In this paper, the syntheses of three different watersoluble cationic cellulosic derivatives from bleached hardwood kraft pulp are reported. The conditions applied, based on a previous kinetic study (Moral et al. 2016), are not as harsh as those usually reported in literature (Song et al. 2008; Sirviö et al. 2011; Acharya et al. 2014), since the reaction times are smaller, making the process more feasible. Characterization of the derivatives involved elemental analysis, X-ray diffraction patterns and infrared spectra. Their charge density, viscosity and zeta-potential were measured. Their performance was tested by laser diffraction spectrometry (LDS) with three different mineral fillers: precipitated and ground calcium carbonate (PCC and GCC, respectively), and kaolin, all of them frequently used in paper mills. In fact, LDS has proved to be very useful in assessing the performance of polymeric aids in flocculation (Antunes et al. 2008b; Pinheiro et al. 2013; Rasteiro et al. 2008a; Seo et al. 2016).

\begin{tabular}{|l|lll|}
\hline & Journal : Medium 10570 & Dispatch : 26-4-2017 & Pages : 13 \\
& Article No. : $\mathbf{1 3 1 3}$ & $\square$ LE & $\square$ TYPESET \\
& MS Code : CELS-D-16-00891 & $\checkmark_{\mathrm{CP}}$ & $\checkmark$ DISK \\
\hline
\end{tabular}




\section{Materials and methods}

\section{Materials}

Industrial bleached Eucalyptus globulus kraft pulp (BEKP) with a refining degree of $34^{\circ} \mathrm{SR}$ was used as raw material.

An aqueous solution of the cationizing agent (3chloro-2-hydroxypropyl) trimethylammonium chloride $(60 \%)$ (CHPTAC), was purchased from SigmaAldrich, and orthophosphoric acid (85\%) was bought from Panreac. A cationic polyacrylamide (CPAM) from BASF with $\mathrm{MW}=3.7 \times 10^{6} \mathrm{~g} / \mathrm{mol}$ and $\mathrm{CD}=1.1 \mathrm{mmol} / \mathrm{g}$ (data provided by the supplier), commonly used as retention agent in papermaking, was used for comparison purposes. Two different industrial calcium carbonates and a hydrated aluminum silicate were used as fillers: scalenohedral PCC, rhombohedral GCC and lamellar kaolin, respectively. Their zeta potentials, measured in aqueous suspensions by electrophoretic mobility in a Zetasizer NanoZS (Malvern Instruments) were +9 ( $\mathrm{pH} 10),-28$ ( $\mathrm{pH}$ 10) and $-24 \mathrm{mV}(\mathrm{pH}$ 6) respectively. The negative values of GCC are due to the presence of anionic polyelectrolytes used to stabilize the GCC dispersions (Vanerek et al. 2000). The fillers also differ in size: their median particle sizes $\left(d_{50}\right)$, determined by LDS in a Mastersizer 2000 (Malvern Instruments), were 4.2, 2.0 and $3.5 \mu \mathrm{m}$, respectively. $\mathrm{NaOH}$ and urea, from Panreac, were also used as solvents.

A representative scheme of the whole experimental procedure, including pretreatments, cationization and separation processes, is depicted in Fig. 1.

\section{Pretreatments}

The different polyelectolytes produced are distinguished by the treatment previous to cationization. The cationic celluloses (CC) were labelled by ascending order of degree of polymerization (corresponding to descending order of yield), namely $\mathrm{CC} 1, \mathrm{CC} 2$ and $\mathrm{CC} 3$. The materials prior to cationization were named, respectively, $\mathrm{C} 1, \mathrm{C} 2$ and $\mathrm{C} 3$.

BEKP was depolymerized with orthophosphoric acid $\left(\mathrm{H}_{3} \mathrm{PO}_{4}\right)$ : a sample of BEKP, with a moisture content of $66 \%$, was soaked in acid so that $\mathrm{H}_{3} \mathrm{PO}_{4}$ concentration was $80 \%$ and the consistency of the suspension (on a dry basis) was $2 \%$. The acid hydrolysis occurred at room temperature for $2 \mathrm{~h}$, the first hour without stirring and the second one with agitation with a four-blade stirrer at $600 \mathrm{rpm}$. A gellike, whitish solution was obtained, similar to a suspension of nanofibrillated cellulose. Apparent dissolution was reverted when the pulp was diluted to $0.5 \%$ with distilled water. The suspension was filtered through an $11 \mu \mathrm{m}$ paper filter, obtaining a powder-like amorphous cellulose $(\mathrm{C} 1)$. The filtrate was discarded.

A precooled $\mathrm{NaOH} /$ urea solution was used to produce $\mathrm{C} 2$ and $\mathrm{C} 3$. For that, BEKP was diluted to $2 \%$ in an aqueous solution containing $6 \% \mathrm{NaOH}$ and $6 \%$ urea, the mole ratio of alkali to anhydroglucose units (AGU) being 12. The suspension was stirred for $1 \mathrm{~h}$ at $600 \mathrm{rpm}$ and then filtered through a $11 \mu \mathrm{m}$ paper filter. The filtrate (lower DP fraction) was named $\mathrm{C} 2$, while the fibrous solid retained (higher DP fraction) was labelled as $\mathrm{C} 3$.

Cationization

Cationization was performed on the filtration retained fractions $(\mathrm{C} 1$ and $\mathrm{C} 3)$ and on the filtrate $(\mathrm{C} 2)$ with CHPTAC using a mole ratio to AGU of 3 , as shown in Fig. 1. $\mathrm{NaOH}$ and urea were also added to $\mathrm{C} 1$ and $\mathrm{C} 3$ aiming for the same concentration $(\mathrm{NaOH} 6 \%$, urea $6 \%$, CHPTAC/AGU 3) in all three samples. Cationization lasted only $60 \mathrm{~min}$, by applying gentle mechanical agitation $(200 \mathrm{rpm})$ and maintaining the temperature at $65{ }^{\circ} \mathrm{C}$. The mechanism by which CHPTAC and cellulose are activated with alkali and react is described elsewhere (Moral et al. 2016).

$\mathrm{CC} 1$ and $\mathrm{CC} 2$ seemed to be completely dissolved in the alkaline media. Since the derivatives are intended to be not only alkali-soluble but also water-soluble, the media were neutralized with hydrochloric acid. While $\mathrm{CC} 2$ remained in solution at neutral $\mathrm{pH}$, a part of $\mathrm{CC} 1$ (insoluble part) was precipitated, filtered and discarded. Cationization of $\mathrm{C} 3$ originated a large amount of undissolved material, which increased even more after the neutralization. In this case, only $20 \%$ of the weight of $\mathrm{C} 3$ passed through the filter. The three cationic derivatives were soaked in a regenerating medium in which the volume percentage of ethanol was at least $50 \%$ (Fig. 1).

The aqueous-alcoholic suspensions were filtered by using a paper filter with an aperture size of $2.5 \mu \mathrm{m}$. The filtrates were discarded, although a liquid sample

\begin{tabular}{|l|lll|}
\hline & Journal : Medium 10570 & Dispatch : 26-4-2017 & Pages : 13 \\
Article No. : $\mathbf{1 3 1 3}$ & $\square$ LE & $\square$ TYPESET \\
MS Code : CELS-D-16-00891 & $\sim_{\mathrm{CP}}$ & $\checkmark$ DISK \\
\hline
\end{tabular}


Fig. 1 Simplified diagram of the experimental procedure used to produce three different cationic cellulose derivatives

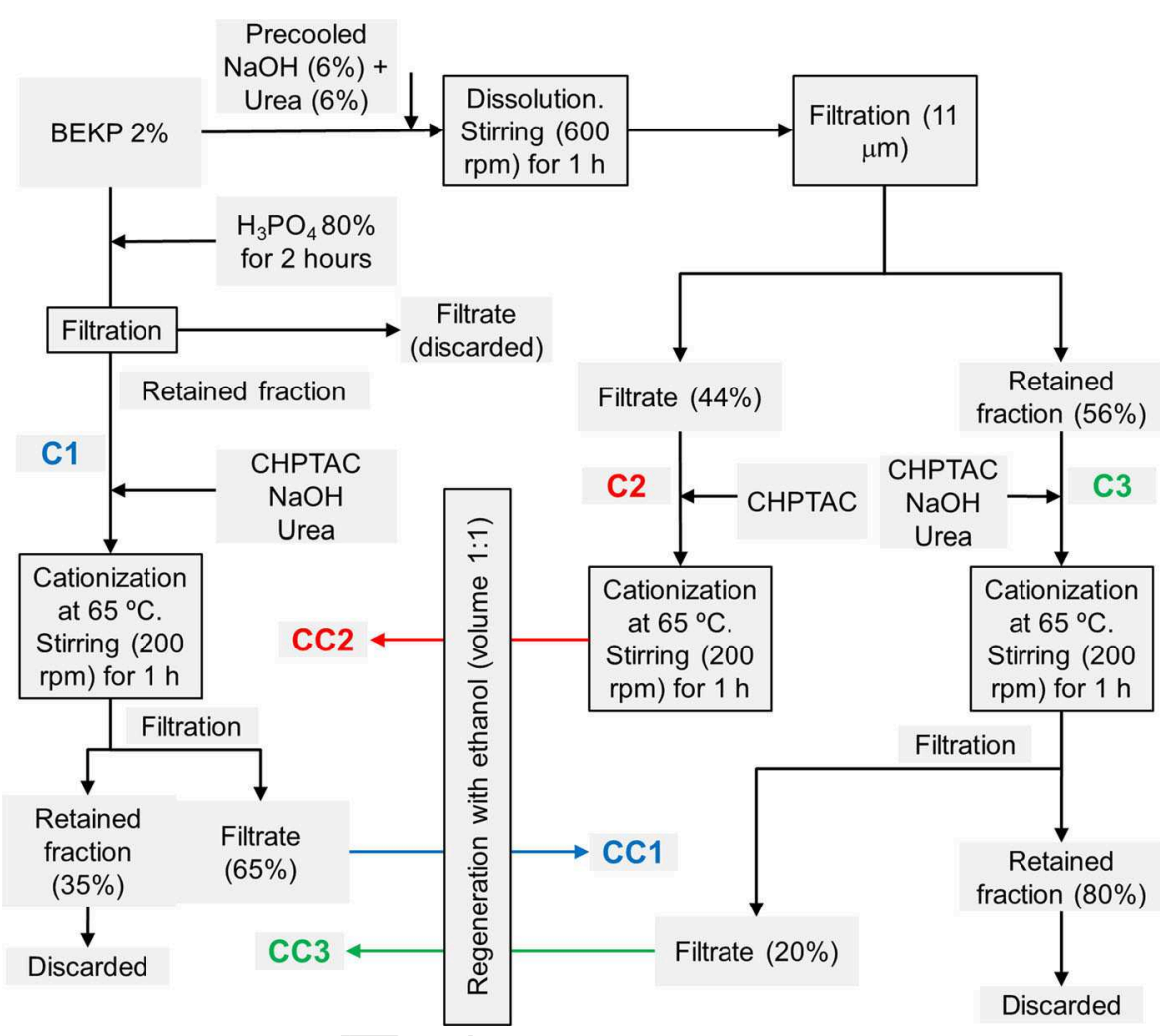

from the CC2 filtration was submitted to mass spectroscopy-gas chromatography (GCMS) to identify any possible by-products. The retained fractions of the filtrations (wet solids) were dried firstly at room temperature for $24 \mathrm{~h}$, and after at $60{ }^{\circ} \mathrm{C}$ for $4 \mathrm{~h}$. The solubility in water was confirmed by centrifugation of $1 \%$ solutions at $3000 \times g$ for $10 \mathrm{~min}$.

\section{Characterization}

The samples were characterized for their degree of polymerization (DP), crystallinity, degree of substitution (DS), charge density (CD), zeta potential, yield and also with FTIR-ATR measurements.

The degree of polymerization of the pretreated samples was determined by dividing the corresponding mean molecular weight (M) by the molecular mass of AGU (162). In turn, the mean molecular weight of the $\mathrm{C} 1, \mathrm{C} 2$ and $\mathrm{C} 3$ pretreated cellulose chains was estimated from the limiting viscosity number $(\mathrm{mL} / \mathrm{g})$ by using the Mark-Houwink equation with the parameters reported by Eckelt et al. (2011) for cellulose solutions in a copper (II) ethylenediamine solution (Cuen): $\eta=0.0653 M^{0.735}$

The limiting viscosity number necessary in Eq. 1 was determined according to the ISO standard 5351-1.

For the crystallinity assessment, aliquots of the pretreated samples $\mathrm{C} 1, \mathrm{C} 2$ and $\mathrm{C} 3$ were dialyzed by using a sack from Sigma-Aldrich which ensures retention of compounds whose molecular mass is $12,000 \mathrm{Da}$ or higher, and placed in deionized water for $24 \mathrm{~h}$, in order to remove phosphate salts and other undesired substances. A PANalytical's powder diffractometer with the software X-Pert HighScore provided X-ray diffraction patterns. The original pulp was also analyzed for comparison purposes.

A LECO CNS-2000I elemental analyzer was used to measure the content of carbon, hydrogen and nitrogen. The degree of substitution (DS) was calculated from the ratio of $\% \mathrm{~N}$ to $\% \mathrm{C}(\mathrm{N} / \mathrm{C})$, assuming that only one cationic quaternary ammonium group can be incorporated per anhydroglucose unit (Moral et al. 2016):

$N / C=\frac{14 D S}{144 D S+72 \cdot(1-D S)}$

\begin{tabular}{|l|lll|}
\hline & Journal : Medium 10570 & Dispatch : 26-4-2017 & Pages : 13 \\
Article No. : 1313 & $\square$ LE & $\square$ TYPESET \\
& MS Code : CELS-D-16-00891 & $\checkmark$ CP & $\checkmark$ DISK \\
\hline
\end{tabular}




\section{Flocculation tests} size. where 14 is the atomic weight of nitrogen, 144 is twelve times the atomic weight of carbon (substituted monomer), and 72 is six times that weight (nonsubstituted monomer).

The charge density (CD) of the cationic derivatives was determined by potentiometric titration in a Charge Analysis System (CAS) from AFG. For that, a small amount of sample (less than $0.1 \mathrm{~g}$ ) was dissolved in $10 \mathrm{~mL}$ of deionized water and the solution was titrated with an anionic polyelectrolyte, sodium polyvinylsulphate (PVSNa, $0.001 \mathrm{~N}$ ).

The zeta potential of $1 \%(\mathrm{w} / \mathrm{w})$ dispersions in distilled water of the dried $\mathrm{CC} 1, \mathrm{CC} 2$ and $\mathrm{CC} 3$ was measured with a Zetasizer Nano ZS device from Malvern Instruments.

FT-IR-ATR spectra were recorded by a Bruker Tensor 27 spectrometer with a MKII Golden Gate accessory, setting the resolution to $4 \mathrm{~cm}^{-1}$ and the number of scans to 128 .

The performance of $\mathrm{CC} 1, \mathrm{CC} 2$ and $\mathrm{CC} 3$ as polymeric flocculants was evaluated by LDS in a Mastersizer 2000 device from Malvern Instruments, equipped with the Hydro 2000 module. To process the raw scattering patterns, the Mie theory (De Boer et al. 1987), which is rigorous and suitable for small particles (below $10 \mu \mathrm{m})$, was used considering the refractive index of the mineral fillers as being 1.57 (Wypych 2016).

Aqueous suspensions $[1 \%(\mathrm{w} / \mathrm{w})]$ of PCC, GCC and kaolin were submitted to magnetic stirring for $20 \mathrm{~min}$ and placed in an ultrasound bath $(50 \mathrm{kHz})$ during $15 \mathrm{~min}$ in order to disaggregate the particles. For each experiment, $6 \mathrm{~mL}$ of the filler suspension were added to the equipment vessel containing $600 \mathrm{~mL}$ of distilled water. This was enough to reach an adequate obscuration of the $\mathrm{He} / \mathrm{Ne}$ laser beam. The pump speed was set to $2000 \mathrm{rpm}$ during the measurement of particle

As for the flocculants, solutions of CPAM, CC1, $\mathrm{CC} 2$ and $\mathrm{CC} 3[0.1 \%(\mathrm{w} / \mathrm{w})]$ were prepared and stirred. A certain amount of the flocculant in each case $(1 \mathrm{mg} /$ $\mathrm{g}$ for CPAM, $20 \mathrm{mg} / \mathrm{g}$ for the cationic cellulosic derivatives) was added after the stabilization of the filler median size (some initial aggregation occurs spontaneously to a certain degree). Then, the evolution of the median particle size of the fillers together with the added polymer was monitored. Smaller amounts of the WSCC were previously tested (see supplementary information).

\section{Results and discussion}

Characterization of the pretreated samples

For the necessary calculations, BEKP was assumed to consist entirely of anhydroglucose units (AGU). This assumption is safe, given the negligible amount of lignin after bleaching, the most probable dissolution of the remaining hemicellulose in the preliminar $\mathrm{NaOH} /$ urea treatment and the fact that cationic groups are also incorporated into anhydropentose units (Deutschle et al. 2014).

For $\mathrm{C} 1, \mathrm{BEKP}$ was depolymerized with orthophosphoric acid $\left(\mathrm{H}_{3} \mathrm{PO}_{4}\right)$, since this compound works both as a hydrolysis agent, as long as its concentration is higher than $30 \%(\mathrm{w} / \mathrm{w})$, and as a cellulose activator, causing total amorphization if its concentration is superior to $79 \mathrm{wt} \%$ (Vinogradov et al. 2002).

For $\mathrm{C} 2$ and $\mathrm{C} 3$, a precooled $\mathrm{NaOH} /$ urea solution was used as solvent due to the influence of urea on hydrophobic interactions of low-DP cellulose (Zang et al. 2002). As mentioned, the $\mathrm{NaOH} / \mathrm{AGU}$ mole ratio $\mathbf{A Q 3} \mathbf{p} 49$ was 12 in order to ensure a good cellulose solvation, since theoretically at least $4 \mathrm{OH}^{-}$ions per monomer are necessary in alkaline dissolution (Myasoedova et al. 1991).

All samples differ in solubility. As visible in Table 1, the DP of C1 was much inferior to that of BEKP. On the contrary, and as intended, $\mathrm{C} 2$ produced from the lower-DP part (soluble in $\mathrm{NaOH} /$ urea, at least to a degree in which solvated particles, macroscopically undistinguishable from the solvent, passed through the filter) exhibited a higher value than $\mathrm{C} 1$ but a smaller value than the original pulp. As for $\mathrm{C} 3$, it has the highest mean DP value, superior to that of the original pulp as a result of being obtained from the higher-DP fraction of this pulp.

Table 1 also presents the crystallinity index (CI) as calculated from the diffraction patterns shown in Fig. 2a. A linear baseline correction and a Gaussian deconvolution of peaks were carried out with Systat's Peakfit, as exemplified in Fig. 2b for the non-treated BEKP sample. The assignment of Miller indices to the peaks and the notation of these indices are based on the

\begin{tabular}{|l|lll|}
\hline & Journal : Medium 10570 & Dispatch : 26-4-2017 & Pages : 13 \\
& Article No. : $\mathbf{1 3 1 3}$ & $\square$ LE & $\square$ TYPESET \\
& MS Code : CELS-D-16-00891 & $\Upsilon_{\mathrm{CP}}$ & $\checkmark$ DISK \\
\hline
\end{tabular}


Table 1 Characteristics of the bleached kraft pulp (BEKP) and of the pretreated cellulose samples

Fig. 2 X-ray diffraction patterns of the bleached kraft pulp (BEKP) and of the pretreated cellulose samples (a) deconvolution of the BEKP X-ray diffraction pattern (b)

\begin{tabular}{lllrll}
\hline Sample & $\eta(\mathrm{mL} / \mathrm{g})$ & $\mathrm{M} \times 10^{-4}(\mathrm{Da})$ & \multicolumn{1}{c}{$\mathrm{DP}$} & $\mathrm{CI}$ & $\mathrm{I}($ Cell-I/Cell-II $)$ \\
\hline BEKP & 494 & 18.9 & 1170 & 0.813 & 4.30 \\
$\mathrm{C} 1$ & 132 & 3.1 & 194 & 0.518 & 1.33 \\
$\mathrm{C} 2$ & 380 & 13.3 & 820 & 0.386 & 0.36 \\
$\mathrm{C} 3$ & 658 & 28.0 & 1703 & 0.540 & 0.88 \\
\hline
\end{tabular}
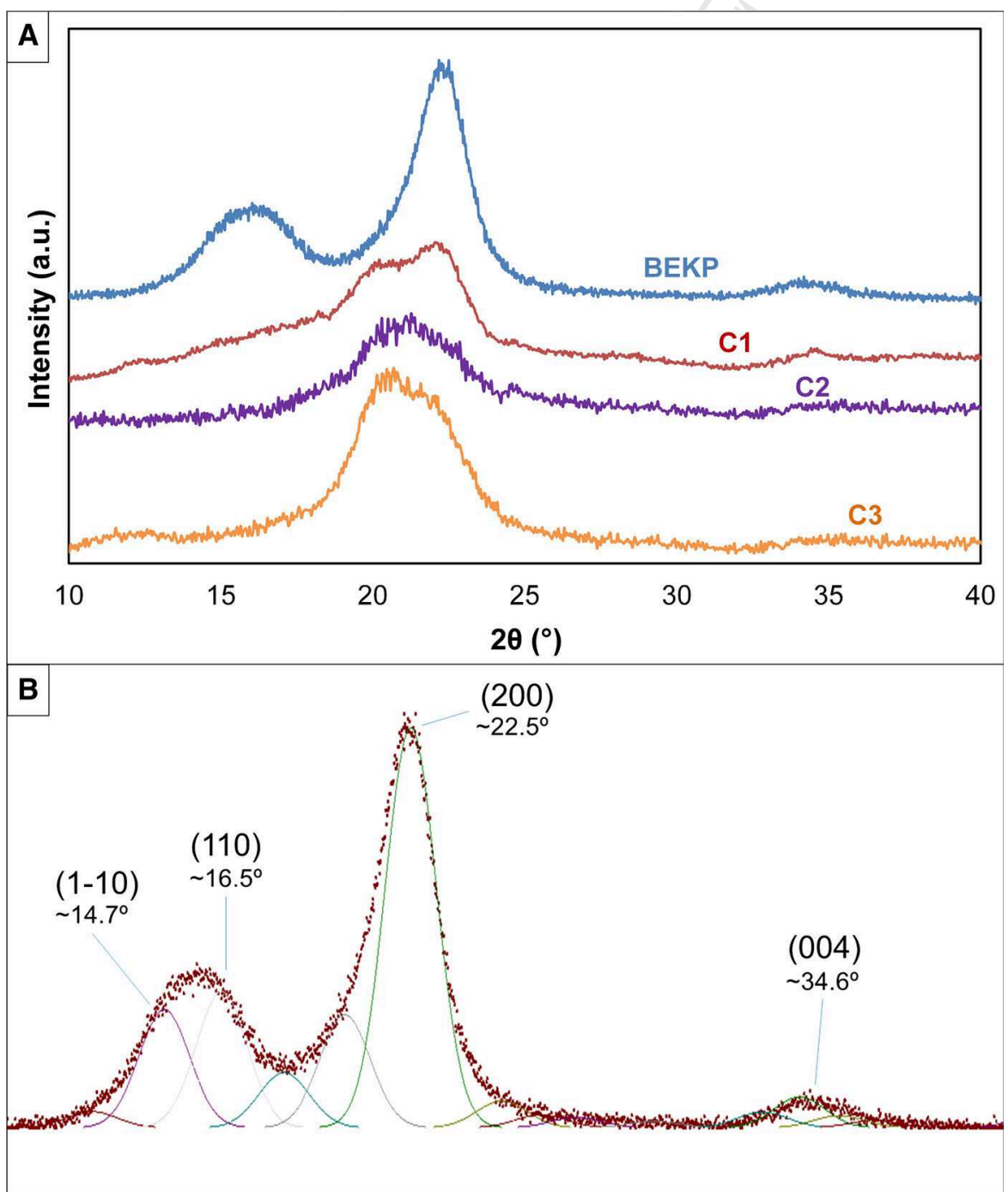

conventions used by French (2014). It is assumed that BEKP, as cellulose from wood, consists fundamentally of cellulose I $\beta$, while the pretreated samples are mixtures of cellulose I $\beta$, cellulose II and amorphous cellulose. The crystallinity of the samples was estimated from XRD by identifying the four most prevalent peaks of cellulose I and the cellulose II 378 (110) peak, and dividing their area by the total area 379 (Eq. 3) (Park et al. 2010):

\begin{tabular}{|l|lll|}
\hline Journal : Medium 10570 & Dispatch : 26-4-2017 & Pages : 13 \\
Article No. : 1313 & $\square$ LE & $\square$ TYPESET \\
MS Code : CELS-D-16-00891 & $\checkmark_{\mathrm{CP}}$ & $\checkmark$ DISK \\
\hline
\end{tabular}


Both orthophosphoric acid and sodium hydroxide caused a diminishment in $C I$. The lowest crystallinity index corresponded to $\mathrm{C} 2$, the only pretreated sample which was totally alkali-soluble.

The diffractogram of BEKP displayed the typical shape of cellulose I (Fig. 2a). Likely, some phosphate groups incorporated into the structure of $\mathrm{C} 1$ during the pretreatment remained after dilution and regeneration, since the shape of the corresponding pattern before $21^{\circ}$ resembles that of cellulose phosphate esters (Olaru et al. 2007). For C2 and C3, partial amorphization was evident: the peak at $22.5^{\circ}$ for the (200) plane of cellulose I became much shorter (C3), or simply indiscernible from the $(020)$ reflection of cellulose II, at $22^{\circ}(\mathrm{C} 2)$. The other peaks became broader, which is a consequence of an increase in the amorphous fraction (Park et al. 2010).

Besides phosphoric acid and inorganic ions, the filtrate of $\mathrm{C} 1$, analyzed by GCMS, contained soluble products from the hydrolysis, but not necessarily furanic compounds. The temperature of the pretreatment $\left(20-25^{\circ} \mathrm{C}\right)$ was too low for dehydration.

To elucidate to what extent cellulose I is converted into cellulose II by the pretreatment, the intensity ratio (I(Cell - I/Cell - II)) was calculated with Eq. 4. The numerator contains peaks assigned to cellulose I, while the denominator contains peaks assigned to cellulose II (French 2014; Kolpak et al. 1978). The peak assigned to the (020) plane of cellulose II is omitted because it overlaps with the highest peak of cellulose I. The peak (004) is roughly the same for both cellulose I $\beta$ and cellulose II. It must be stressed that this parameter serves as an indication of the ratio of cellulose I to cellulose II for comparison purposes, but never as an accurate and absolute determination of that ratio.

$\mathrm{I}($ Cell $-\mathrm{I} /$ Cell $-\mathrm{II})=\frac{\mathrm{I}_{14.7^{\circ}}+\mathrm{I}_{16.5^{\circ}}+\mathrm{I}_{22.5^{\circ}}+\mathrm{I}_{040}}{\mathrm{I}_{12.4^{\circ}}+\mathrm{I}_{20.3^{\circ}}+\mathrm{I}_{040}}$

The value corresponding to $\mathrm{C} 1$ is not reliable, since the peak (110) of cellulose II $\left(20.1^{\circ}\right)$ may be confused with the most prominent band of cellulose phosphate. As expected, the proportion of cellulose II, more thermodynamically stable, increases with the alkaline treatments $(\mathrm{C} 2, \mathrm{C} 3)$, as it also happens, for instance, in cotton mercerization (Poletto et al. 2014). When this alkaline treatment results in apparent dissolution (C2) and the sample is regenerated with an alcohol, specific peaks of cellulose I cannot be perceived in XRD patterns. C2 may consist completely of cellulose II and amorphous cellulose.

Characterization of the cationic derivatives

The DP values estimated from Eq. 1 for the pre-treated samples were also used for the cationized CC1, CC2 and CC3 samples. In fact, it is legitimate to consider that the DP is not modified with the cationization process, because the temperature is too low for an alkaline hydrolysis to happen at an appreciable extent. For instance, Song et al. (2008) using size exclusion chromatography, showed that the hydrolysis of cellulose during cationization with CHPTAC, $\mathrm{NaOH}$ and urea is negligible, even when the reaction took place at $60{ }^{\circ} \mathrm{C}$ for $8 \mathrm{~h}$. As can be seen in Table 2, the cellulosic derivative with the highest DP (CC3) was the one presenting, after cationization, the highest degree of substitution, charge density and zeta potential. This is due to the fact that high-DP cellulose needs to have more ionized monomers to become soluble in water, and thus the lowly-substituted parts were rejected. As a drawback, given the mildness of the conditions used in this study, these lowly-substituted parts accounted for the majority of the material. Crystalline and lowlysubstituted parts of CC3 could not pass through the filter after neutralizing with $\mathrm{HCl}$.

Table 2 also shows the yield of WSCC from the bleached kraft pulp. It should be noted that $\mathrm{CC} 2$ and $\mathrm{CC} 3$ share the same pretreatment. $100 \mathrm{~g}$ of BEKP could be used to produce $44 \mathrm{~g}$ of CC2 2 and $11 \mathrm{~g}$ of CC 3 (a total of $55 \mathrm{~g}$ of cationic cellulose from one single process), or $60 \mathrm{~g}$ of $\mathrm{CC} 1$, which is less electrically charged. Sirviö et al. (2011) obtained higher yield values, achieving complete dissolution of high-DP cellulose by producing a polymer with a very high

Table 2 Characteristics of the three cationic cellulosic derivatives

\begin{tabular}{lllll}
\hline Sample & Yield (\%) & DS $^{\mathrm{a}}$ & $\mathrm{CD}^{\mathrm{a}}(\mathrm{mmol} / \mathrm{g})$ & $\zeta$-Potential $(\mathrm{mV})$ \\
\hline $\mathrm{CC} 1$ & 60 & 0.33 & 2.07 & +4.5 \\
$\mathrm{CC} 2$ & 44 & 0.34 & 2.80 & +6.8 \\
$\mathrm{CC} 3$ & 11 & 0.46 & 5.01 & +16.7 \\
\hline
\end{tabular}

${ }^{a}$ DS and CD mean degree of substitution and charge density, respectively

\begin{tabular}{|l|lll|}
\hline & Journal : Medium 10570 & Dispatch : 26-4-2017 & Pages : 13 \\
Article No. : $\mathbf{1 3 1 3}$ & $\square$ LE & $\square$ TYPESET \\
MS Code : CELS-D-16-00891 & $\checkmark_{\text {CP }}$ & $\checkmark$ DISK \\
\hline
\end{tabular}


degree of substitution, but at the cost of a $24 \mathrm{~h}$-long first treatment, a $3 \mathrm{~h}$-long second treatment at $75{ }^{\circ} \mathrm{C}$ and then by cationizing with Girard's reagent.

Substitution was in the expected range. Lower degrees of substitution would have implied lack of solubility, while obtaining values close to 1 was impossible under mild conditions. Higher reaction times and higher concentrations of CHPTAC could have improved the yield, but probably not the degree of substitution. Yan et al. (2009) cationizing cellulose with a reagent/AGU molar ratio of 10 , achieved DS values of 0.32 and 0.47 by applying reaction times of 6 and $9 \mathrm{~h}$, respectively. These values are in the same range as those presented in Table 2, but their conditions and the use of low-DP cellulose eased solubility and avoided discards of undissolved parts, achieving a yield of $100 \%$.

A gentle process, like the one suggested in this work, can generate samples with degrees of substitution higher than 0.3 at the expense of the yield. If a continuous reactor had been used instead of a batch one, the insoluble fraction could have been recycled, keeping the mild conditions. This would be a feasible alternative to the expensive and time-consuming processes.

The zeta potential of the starting material (fibers from BEKP) in water is slightly negative in a wide $\mathrm{pH}$ range and cationization involved a switch towards positive values. As cationic functional groups were incorporated into cellulose, the polymer reached the isoelectric point and then its charge density increased with the degree of substitution. The small difference between the $\mathrm{CC} 1$ and $\mathrm{CC} 2$ zeta potentials could be deemed not significant. The value found for CC3 suspended in water was much higher. This could be explained by the pretreatments applied in the latter, which decreased the stability of the dissociable groups that have a negative contribution to the surface charge.

All ATR-FTIR spectra, normalized and presented in Fig. 3, showed typical peaks for cellulose in absorption bands at $3330 \mathrm{~cm}^{-1}(\mathrm{~g})$, related to $\mathrm{O}-\mathrm{H}$ stretching, and at $2882 \mathrm{~cm}^{-1}$ (f), associated with symmetrical stretching of $\mathrm{C}-\mathrm{H}$ bonds. The intensity of the absorption at $897 \mathrm{~cm}^{-1}$ (a), due to $\mathrm{C} 1-\mathrm{H}$ bending and sensitive to a rearrangement of intramolecular hydrogen bonds (Yang et al. 2010), increased with the amorphous fraction of the sample. Particularly for $\mathrm{CC} 2$, the derivative with the lowest crystallinity, this peak was almost as high as the one found at
$1040 \mathrm{~cm}^{-1}$ (b). Bands at 1160 and $1019 \mathrm{~cm}^{-1}$ are assigned to $\mathrm{C}-\mathrm{O}-\mathrm{C}$ asymmetric stretching and different vibrations of $\mathrm{C}-\mathrm{C}$ and $\mathrm{C}-\mathrm{O}$ bonds, respectively. In the spectra for $\mathrm{CC} 2$ and $\mathrm{CC} 3$, the decrease in sharpness is evident and these peaks become mere shoulders. The band at $1623 \mathrm{~cm}^{-1}$ (e) is due to $\mathrm{O}-\mathrm{H}$ bending in absorbed water (Granja and Barbosa 2001). Purification after regenerating succeeded to remove urea, since its absorption bands, which would be very prominent between 1700 and $1400 \mathrm{~cm}^{-1}$ and between 3500 and $3100 \mathrm{~cm}^{-1}$ (Turney et al. 2013), cannot be distinguished.

Spectra of CC1, CC2 and CC3 showed additional peaks at 1427 and $1390 \mathrm{~cm}^{-1}$ (d), linked to the quaternary ammonium groups (Sang et al. 2012). Due to the conversion of cellulose I to cellulose II, the spectra of $\mathrm{CC} 2$ and $\mathrm{CC} 3$ do not possess a peak at $1345 \mathrm{~cm}^{-1}$ (Granja and Barbosa 2001). Whether phosphate groups remain in the structure of $\mathrm{CC} 1$ is not proved by its spectrum, but their absence is not confirmed either, since the most prominent band of $\mathrm{PO}_{4}$ is given at $1020 \mathrm{~cm}^{-1}$, thus interfering with one of the most noticeable bands in the spectrum of cellulose (Hallac and Ragauskas 2011).

Performance in flocculation tests

The evolution of the median equivalent spherical 536 diameter $\left(\mathrm{d}_{50}\right)$ of the three fillers when in contact with the WSCC is plotted in Fig. 4. On the left side (Figs. $4 \mathrm{a}-\mathrm{c}$ ) the influence of the WSCC addition on the different fillers flocculation is shown. The results were normalized considering the particles median size at the moment of the flocculant addition and the corresponding values are shown in Fig. 4d-f, which provide a better perception of the influence of each polyelectrolyte separately. As stated, CPAM was always used for comparison purposes since it is one of the most common flocculants used in papermaking. Table 3 presents the zeta potential of the suspensions used in the flocculation tests at given $\mathrm{pH}$ values.

When kaolin was used, it is evident that CPAM and CC3 promoted a high filler flocculation, with a maximum filler particle size increment close to 6.5 and 7.5 times, respectively. As stated in the literature CPAM is able to flocculate the particles by bridging due to its high molecular weight (Neimo 1999). As for CC3, with a molecular weight one order of magnitude off but a much higher charge density
537

\begin{tabular}{|l|lll|} 
Journal : Medium 10570 & Dispatch : 26-4-2017 & Pages : 13 \\
Article No. : 1313 & $\square$ LE & $\square$ TYPESET \\
MS Code : CELS-D-16-00891 & $\checkmark_{\mathrm{CP}}$ & $\checkmark$ DISK \\
\hline
\end{tabular}


Fig. 3 Infrared spectra of the original bleached kraft pulp (BEKP) and of the cationic cellulosic derivatives

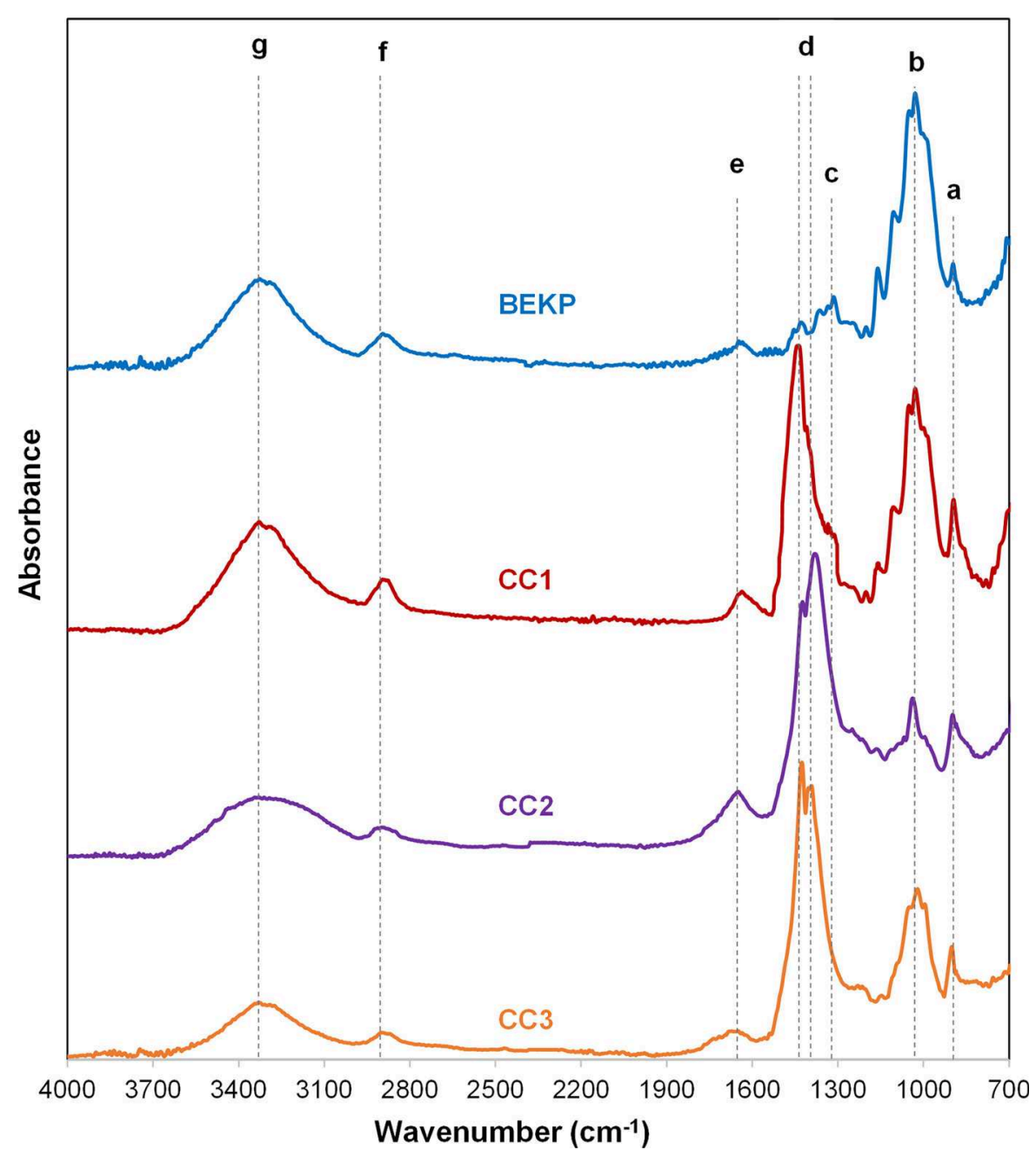

(Tables 1,2), neutralization was most probably the dominant mechanism (Neimo 1999). However, due to the high charge, patching was also likely to occur, which was proven by the good reflocculation ability of the particles after a step of high shear, shown in Fig. 5. According to Rasteiro et al. (2008b), flocs formed by bridging mechanisms do not reflocculate as easily as those formed by patching. In fact, the electrokinetic potential of the kaolin/CC3 mixture was only slightly negative $(-7.3 \mathrm{mV})$, which increases the probability of particle aggregation. In contrast, with $\mathrm{CC} 2$ this value was much higher $(-27.2 \mathrm{mV})$ and the flocculation effects were attenuated, in accordance with the smaller values of the molecular weight and also charge density. CC1 has no influence in filler flocculation, regardless the mineral used, and this is a result of the very small molecular weight, degree of polymerization and also charge density. For this reason, the plot with the normalized values is not presented. This confirms that the pretreatment with ortophosphoric acid was not successful to induce filler flocculation.

For GCC similar results are observed with CC2 and CC3, revealing a negligible increment of the particles size. In spite of having also a negative charge, as kaolin, GCC particles are scalenohedral shaped, and not lamellar, and this fact may have hindered the aforementioned flocculating mechanisms. In this case only CPAM seems to be effective.

Contrary to kaolin and GCC, PCC has positive charge $(+9 \mathrm{mV})$ and therefore the influence of the WSCC on filler flocculation is expectedly different.

\begin{tabular}{|l|lll|}
\hline & Journal : Medium 10570 & Dispatch : 26-4-2017 & Pages : 13 \\
& Article No. : $\mathbf{1 3 1 3}$ & $\square$ LE & $\square$ TYPESET \\
& MS Code : CELS-D-16-00891 & $\checkmark_{\text {CP }}$ & $\checkmark$ DISK \\
\hline
\end{tabular}



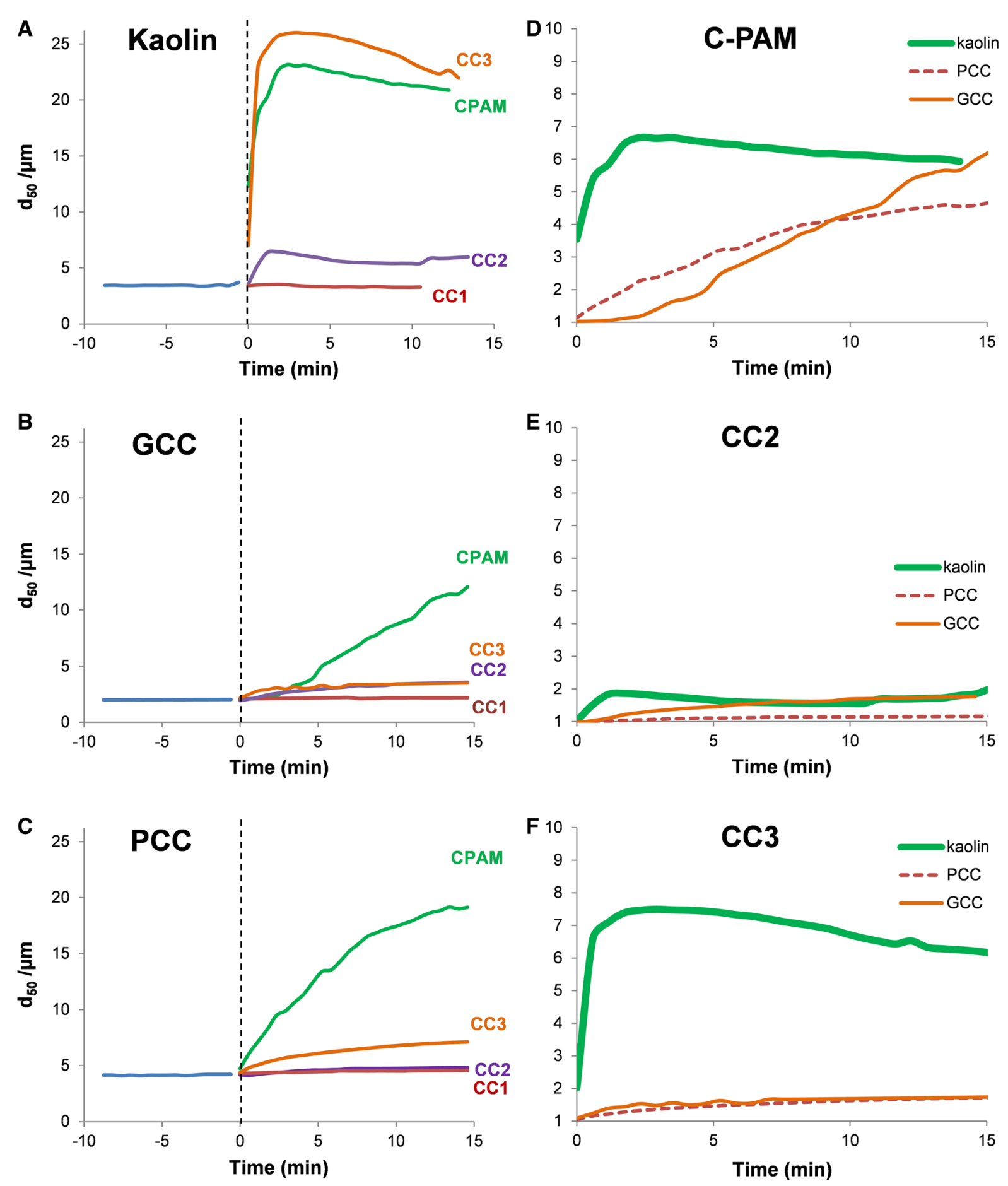

Fig. 4 Flocculation kinetics of three mineral fillers with a cationic polyacrylamide (CPAM) and with the cationic cellulosic derivatives (CC1, CC2 and CC3), depending on the choice of filler $(\mathbf{a}-\mathbf{c})$ and on the choice of flocculation agent $(\mathbf{d}-\mathbf{f})$

591 However, similarly to GCC, both CC2 and CC3 don't 592 have significant impact on flocculation. By the con-
593 trary, CPAM has a positive effect on PCC flocculation, 593 by bridging, in agreement with many studies reported in the literature (Rasteiro et al. 2008a; Lourenço et al. 2017).

\begin{tabular}{|l|lll|}
\hline Journal : Medium 10570 & Dispatch : 26-4-2017 & Pages : 13 \\
Article No. : 1313 & $\square$ LE & $\square$ TYPESET \\
MS Code : CELS-D-16-00891 & $\checkmark_{\mathrm{CP}}$ & $\checkmark$ DISK \\
\hline
\end{tabular}


Table 3 Zeta potential of the suspensions used in the flocculation tests

\begin{tabular}{llcr}
\hline Filler & WSCC & $\zeta$-Potential $(\mathrm{mV})$ & $\mathrm{pH}$ \\
\hline Kaolin & - & -23.7 & 5.6 \\
& CC1 & -29.5 & 7.1 \\
& CC2 & -27.2 & 7.0 \\
& CC3 & -7.3 & 7.0 \\
& CPAM & -9.7 & 7.1 \\
GCC & - & -27.8 & 10.1 \\
& CC2 & -2.7 & 9.9 \\
& CC3 & -11.7 & 9.8 \\
& CPAM & -18.9 & 9.9 \\
PCC & - & 8.7 & 10.1 \\
& CC2 & 0.8 & 9.9 \\
& CC3 & 15.4 & 10.0 \\
& CPAM & 7.3 & 10.1 \\
\hline
\end{tabular}

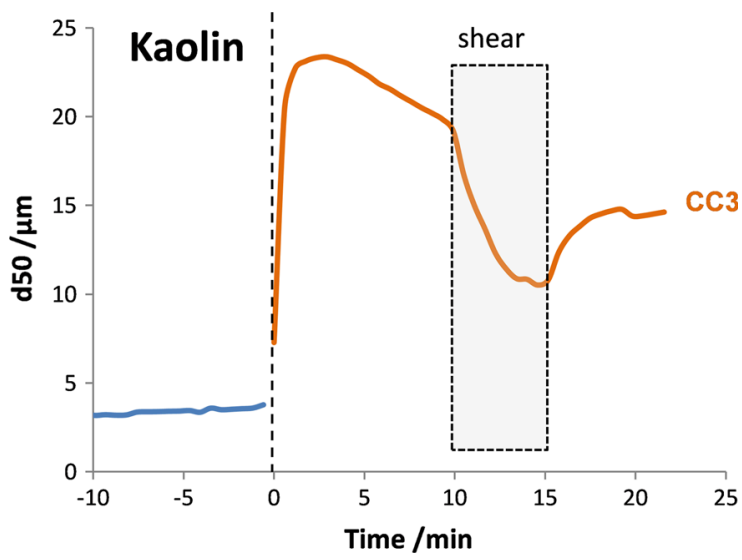

Fig. 5 Reflocculation behavior of kaolin with $\mathrm{CC} 3$ after floc rupture flocculation of fillers occurred but in a clearly smaller extent. Those results can be found in the supplementary material of the electronic version of this article.

It is safe to state that by cationizing cellulose it is possible to obtain water soluble derivatives with promising applications as filler flocculant for papermaking. In order to promote an effective flocculation, the WSCC must possess high charge and/or high DP, which in this work was achieved by pretreating cellulose fibers with $\mathrm{NaOH}$ and urea, followed by a cationization with CHPTAC, and finally by regenerating the resulting filtrate with ethanol. The obtained dry product, soluble in water, presented a medium degree of polymerization, high charge density and a moderate zeta potential, but the yield of production under mild conditions was quite small (11\%). In this work, the best flocculation results were obtained with kaolin due to its higher surface charge and lamellar shape that allowed the WSCC to be adsorbed more easily on its surface.

\section{Conclusions}

Three water-soluble cationic derivatives of cellulose, containing at least 30 quaternary ammonium groups per 100 anhydroglucose units and a charge density above $2 \mathrm{mmol} / \mathrm{g}$, were produced with $\mathrm{NaOH}$ and CHPTAC under mild conditions, following different pretreatments.

The pretreatment with orthophosphoric acid caused the yield to be the highest, easing solubility by acid hydrolysis and amorphization, but the degree of polymerization (DP) of $\mathrm{CC} 1$ was too low to promote a suitable flocculation of filler for papermaking. In fact, by comparing the results with those obtained by applying the other alkaline pretreatment ( $\mathrm{NaOH} /$ urea), it is possible to conclude that the WSCC whose DP was the highest (CC3) originated the best results in flocculation tests, even better than those for CPAM when the filler used was kaolin. The performance of the derivative with an intermediate DP, CC2, was worse when flocculating PCC and kaolin, but as good with GCC as that of CC3.

When using GCC, the flocculation was faster with $\mathrm{CC} 2$ and $\mathrm{CC} 3$ than with a conventional CPAM polymer. However, the flocculation tests with PCC only yielded acceptable results with CPAM, most likely due to the high molecular weight of this

\begin{tabular}{|l|lll|}
\hline & Journal : Medium 10570 & Dispatch : 26-4-2017 & Pages : 13 \\
Article No. : 1313 & $\square$ LE & $\square$ TYPESET \\
MS Code : CELS-D-16-00891 & $\checkmark$ CP & $\checkmark$ DISK \\
\hline
\end{tabular}




\section{Supplementary information}

660 SFRH/BDE/108095/2015.

\section{References} making. Tappi J 68:91-94 102:627-635 cotton. Polymer 19:123-131 Boca Raton polyelectrolyte. Further research could be beneficial if a water-soluble cationic polymer with medium charge density from high-DP cellulose could be obtained.

The evolution of the median particle size of the fillers with smaller dosages $(10 \mathrm{mg} / \mathrm{g})$ of WSCC is provided.

Acknowledgments Roberto Aguado is thankful to Asociación Universitaria Iberoamericana de Posgrado for the Grant to fund an internship in Coimbra. Ana F. Lourenço acknowledges Fundação para a Ciência e Tecnologia for the Ph.D. Grant

Acharya S, Abidi N, Rajbhandari R, Meulewaeter F (2014) Chemical cationization of cotton fabric for improved dye uptake. Cellulose 21:4693-4706

Allen LH (1985) Particle size distributions of fines in mechanical pulps and some aspects of their retention in paper-

Antunes E, Garcia FAP, Ferreira P, Blanco A, Negro C, Rasteiro MG (2008a) Use of new branched cationic polyacrylamides to improve retention and drainage in papermaking. Ind Eng Chem Res 47:9370-9375

Antunes E, Garcia FAP, Ferreira P, Rasteiro MG (2008b) Flocculation of PCC filler in papermaking: influence of the particle characteristics. Chem Eng Res Des 85:1155-1160

De Boer GBJ, De Weerd C, Thoenes D, Goossens HWJ (1987) Laser diffraction spectroscopy: fraunhofer diffraction versus Mie scattering. Part Part Syst Charact 4:14-19

Deutschle AL, Romhild K, Meister F, Janzon R, Riegert C (2014) Effects of cationic xylan from annual plants on the mechanical properties of paper. Carbohydr Polym

Eckelt J, Knopf A, Röder T, Weber HK, Sixta H, Wolf BA (2011) Viscosity-molecular weight relationship for cellulose solutions in either NMMO monohydrate or Cuen. J Appl Polym Sci 109:670-676

French AD (2014) Idealized powder diffraction patterns for cellulose polymorphs. Cellulose 21:885-896

Granja PL, Barbosa MA (2001) Cellulose phosphates as biomaterials. Mineralization of chemically modified regenerated cellulose hydrogels. J Mater Sci 36:2163-2172

Hallac BB, Ragauskas AJ (2011) Analyzing cellulose degree of polymerization and its relevancy to cellulosic ethanol. Biofuels Bioprod Biorefining 5:215-225

Kolpak FJ, Weih M, Blackwell J (1978) Mercerization of cellulose: 1. Determination of the structure of mercerized

Kozubal C, Lopez Baca A, Navarro E (2014) Hair conditioners. In: Barel AO, Paye M, Maibach HI (eds) Handbook of cosmetic science and technology, 4th edn. CRC Press,
Li G, Fu Y, Shao Z, Zhang F, Qin M (2015) Preparing cationic cellulose derivative in $\mathrm{NaOH} / \mathrm{urea}$ aqueous solution and its performance as filler modified. BioResources 10: 7782-7794

Liesiene J (2010) Synthesis of water-soluble cationic cellulose derivatives with tertiary amino groups. Cellulose 17: $167-172$

Liesiene J, Kazlauske J (2012) Functionalization of cellulose: synthesis of water-soluble cationic cellulose derivatives. Cellulose Chem Technol 47:515-525

Liimatainen H, Sirviö J, Sundman O, Visanko M, Hormi O, Niinimäki J (2011) Flocculation performance of a cationic biopolymer derived from a cellulosic source in mild aqueous solution. Bioresour Technol 102:9626-9632

Lourenço AF, Gamelas JAF, Nunes T, Amaral J, Mutjé P, Ferreira PJ (2017) Influence of TEMPO-oxidized cellulose nanofibrils on the properties of filler-containing papers. Cellulose 24:349-362

Moral A, Aguado R, Tijero A (2016) Cationization of native and alkaline cellulose: mechanism and kinetics. Cellulose Chem Technol 50:109-115

Myasoedova VV, Polrovskii SA, Zav'yalov NA, Drestov GA (1991) Thermochemistry of the dissolution and characteristics of the solvation of cellulose, polysaccharides, and their derivatives. Russ Chem Rev 60:954-966

Neimo L (1999) Papermaking science and technology: papermaking chemistry. book 4 . Fapet Oy \& TAPPI, Helsinki

Olaru N, Ciolacu D, Tampu D, Olaru L (2007) Structural modifications of cellulose in heterogeneous acetylation process. J Optoelectron Adv Mat 9:3917-3920

Park S, Baker JO, Himmel ME, Parilla PA, Johnson DK (2010) Cellulose crystallinity index: measurement techniques and their impact on interpreting cellulase performance. Biotechnol Biofuels 3:10. doi:10.1186/1754-6834-3-10

Pinheiro I, Ferreira PJ, Garcia FA, Reis MS, Pereira AC, Wandrey C, Ahmadloo H, Amaral JL, Hunkeler D, Rasteiro MG (2013) An experimental design methodology to evaluate the importance of different parameters on flocculation by polyelectrolytes. Powder Technol 238:2-13

Poletto M, Ornaghi HL Jr, Zattera AJ (2014) Native cellulose: structure, characterization and thermal properties. Materials 7:6105-6119

Prado HJ, Matulewicz C (2014) Cationization of polysaccharides: a path to greener derivatives with many industrial applications. Eur Polym J 52:53-75

Qi H, Yang Q, Zhang L, Liebert T, Heinze T (2011) The dissolution of cellulose in $\mathrm{NaOH}$-based aqueous system by two-step process. Cellulose 18:237-245

QY Research (2017) Global cationic starch market 2017 industry research report. http://market.biz/report/globalcationic-starch-market-2017/65593/. Accessed 3 April 2017

Rasteiro MG, Garcia FAP, Ferreira P, Blanco A, Negro C, Antunes E (2008a) The use of LDS as a tool to evaluate flocculation mechanisms. Chem Eng Process 47: $1329-1338$

Rasteiro MG, Garcia FAP, Ferreira P, Blanco A, Negro C, Antunes E (2008b) Evaluation of flocs resistance and reflocculation capacity using the LDS technique. Powder Technol 183:231-238

\begin{tabular}{|l|lll|}
\hline & Journal : Medium 10570 & Dispatch : 26-4-2017 & Pages : 13 \\
Article No. : 1313 & $\square$ LE & $\square$ TYPESET \\
MS Code : CELS-D-16-00891 & $\checkmark$ CP & $\checkmark$ DISK \\
\hline
\end{tabular}


767
Sang Y, McQuaid M, Englezos P (2012) Pre-flocculation of precipitated calcium carbonate filler by cationic starch for highly filled mechanical grade paper. BioResources 7:354-373

Seo D, Jeong YB, Oh K, Im W, Lee HL (2016) Effects of charge density and molecular weight of cationic polyacrylamides on growth and structural characteristics of ground calcium carbonate aggregates. Nord Pulp Pap Res J 31:191-197

Sirviö J, Honka A, Liimatainen H, Niinimäki J, Hormi O (2011) Synthesis of highly cationic water-soluble cellulose derivative and its potential as novel biopolymeric flocculation agent. Carbohydr Polym 86:266-270

Song Y, Sun Y, Zhang X, Zhou J, Zhang L (2008) Homogeneous quaternization of cellulose in $\mathrm{NaOH} /$ urea aqueous solutions as gene carriers. Biomacromolecules 9:2259-2264

Turney TW, Patti A, Gates W, Shaheen U, Kulasegaram S (2013) Formation of glycerol carbonate from glycerol and urea catalysed by metal monoglycerolates. Green Chem 15:1925-1931
Vanerek A, Alince B, Van de Ven TGM (2000) Colloidal behaviour of ground and precipitated calcium carbonate fillers: effects of cationic polyelectrolytes and water quality. J Pulp Pap Sci 26:135-139

Vinogradov VV, Mizerovskii LN, Akaev OP (2002) Reaction of cellulose with aqueous solutions of orthophosphoric acid. Fibre Chem 34:167-171

Wood J, Mora P (1963) Preparation and biological application of highly substituted cationic derivatives of polysaccharides. J Polym Sci A 1:3511-3517

Wypych G (2016) Handbook of fillers, 4th edn. ChemTech Publishing, Toronto

Yan L, Tao H, Bangal PR (2009) Synthesis and flocculation behavior of cationic cellulose prepared in a $\mathrm{NaOH} / \mathrm{urea}$ aqueous solution. Clean Soil Air Water 37:39-44

Yang S, Fu S, Li X, Zhou Y, Zhan H (2010) Preparation of saltsensitive and antibacterial hydrogel based on quaternized cellulose. BioResources 5:1114-1125

\begin{tabular}{|l|lll|}
\hline & Journal : Medium 10570 & Dispatch : 26-4-2017 & Pages : 13 \\
Article No. : 1313 & $\square$ LE & $\square$ TYPESET \\
MS Code : CELS-D-16-00891 & $\smile_{\mathrm{CP}}$ & $\checkmark$ DISK \\
\hline
\end{tabular}


Journal : 10570

Article : 1313

\section{Author Query Form}

黛 Springer

the language of science

\section{Please ensure you fill out your response to the queries raised below and return this form along with your corrections}

Dear Author

During the process of typesetting your article, the following queries have arisen. Please check your typeset proof carefully against the queries listed below and mark the necessary changes either directly on the proof/online grid or in the 'Author's response' area provided below

\begin{tabular}{|c|c|c|}
\hline Query & Details Required & Author's Response \\
\hline AQ1 & Qi et al. (2010) has been changed to Qi et al. (2011) so that this citation matches the list. & \\
\hline AQ2 & $\begin{array}{l}\text { Pinheiro et al. (2008) has been changed to Pinheiro et al. (2013) so that this citation matches } \\
\text { the list. }\end{array}$ & \\
\hline AQ3 & $\begin{array}{l}\text { Reference: Reference Zang et al. (2002) was mentioned in the manuscript; however, this was } \\
\text { not included in the reference list. As a rule, all mentioned references should be present in the } \\
\text { reference list. Please provide the reference details to be inserted in the reference list. }\end{array}$ & \\
\hline AQ4 & French et al. (2014) has been changed to French (2014) so that this citation matches the list. & \\
\hline AQ5 & $\begin{array}{l}\text { Hallac and Ragauskas (2001) has been changed to Hallac and Ragauskas (2011) so that this } \\
\text { citation matches the list. }\end{array}$ & \\
\hline AQ6 & $\begin{array}{l}\text { Lourenço et al (2016) has been changed to Lourenço et al. (2017) so that this citation matches } \\
\text { the list. }\end{array}$ & \\
\hline
\end{tabular}

